13

\title{
Композитный катод водородного топливного элемента с высокой эффективностью преобразования энергии
}

\author{
() Н.В. Глебова, А.А. Нечитайлов, А.О. Краснова, А.А. Томасов, Н.К. Зеленина \\ Физико-технический институт им. А.Ф. Иофрфе РАН, \\ 194021 Санкт-Петербург, Россия \\ e-mail: aan.shuv@mail.ioffe.ru
}

Поступило в Редакцию 29 декабря 2018г.

В окончательной редакции 29 декабря 2018 г.

Принято к публикации 30 мая 2019г.

Исследованы структурные и электрические характеристики композитных электродов, структурномодифицированных за счет введения углеродных нанотрубок с высокой пористостью и долей транспортных пор, и формирования протонпроводящего полимера Nafion преимущественно в островковой форме. Проведены анализ энергетических потерь для различных составов и оптимизация состава катода. Увеличена эффективность катодного процесса и улучшены характеристики катода, достигнуты следующие характеристики мембранно-электродного блока: при электрическом КПД $\sim 0.5$ удельная загрузка платины составила $0.1 \mathrm{~g} / \mathrm{kW}$, а максимальная плотность мощности $1 \mathrm{~W} / \mathrm{cm}^{2}$.

Ключевые слова: топливные элементы, катод, структура, эффективность.

DOI: $10.21883 /$ JTF.2019.12.48499.451-18

\section{Введение}

Как известно, эффективность преобразования энергии в водородных топливных элементах (ТЭ) наряду с задачами повышения технологичности их изготовления является серьезным фактором, который определяет их конкурентоспособность с другими источниками электроэнергии. В понятие эффективность в данном случае принято включать такие параметры как удельная загрузка платины $\left[\mathrm{g}_{\mathrm{Pt}} / \mathrm{kW}\right]$, удельная мощность $\left[\mathrm{W} / \mathrm{cm}^{2}\right]$, КПД (\%).

В настоящее время большие усилия направлены на улучшение этих характеристик. Исследования в основном сводятся к повышению степени использования поверхности платины и организации оптимального водного обмена в активном слое мембранно- электродного блока (МЭБ) посредством модифицирования и оптимизации состава активного слоя.

Для достижения этих целей используются сплавы платины с неплатиновыми металлами; замена платины на неплатиновые металлы и их органические соединения; носители платины с высокоразвитой поверхностью $\left(>1000 \mathrm{~m}^{2} / \mathrm{g}\right)$ [1,2]. Большое внимание уделяется математическому моделированию и контролю содержания воды и ее транспорта в МЭБ $[3,4]$.

Значительная доля работ посвящена исследованию влияния и оптимизации содержания протонпроводящего полимера Nafion в композитных электродах, например, работы [5-7] и модифицированию его характеристик: ионной проводимости [8], структуры [9].

В настоящее время характерная удельная площадь активной поверхности платины в активных слоях составляет 50-70 $\mathrm{m}^{2} / \mathrm{g}$, в то время как теоретически при размере частиц платины $2-4 \mathrm{~nm}$ она может достигать $\sim 70-140 \mathrm{~m}^{2} / \mathrm{g}$. Характерная загрузка платины в кислородно-водородных топливных элементах составляет $\sim 0.2-1 \mathrm{~g} / \mathrm{kW}$ при ее содержании в катодном активном слое около $0.2-0.3 \mathrm{mg} / \mathrm{cm}^{2}$. Электрохимические характеристики активных слоев сильно зависят от условий функционирования (окислительная среда, температура, давление, влажность, КПД). Так, для комнатной температуры, атмосферного давления и воздушного катода коммерческие топливные элементы показывают удельную мощность $\sim 0.2-0.3 \mathrm{~W} / \mathrm{cm}^{2}$; для кислородного катода, температуры $\sim 80^{\circ} \mathrm{C}$ и избыточного давления $2 \mathrm{~atm},-(0.7-1) \mathrm{W} / \mathrm{cm}^{2}$ при КПД 50\% [10].

Одним из перспективных направлений улучшения характеристик является управление структурой электрода, так как структурный фактор является мощным инструментом, который позволяет увеличить эффективность электродного процесса.

Целью настоящей работы явилось улучшение характеристик катода за счет модифицирования структуры электрода: создания высокой пористости с большим количеством транспортных пор и увеличения доли электрохимически активной поверхности платины за счет введения в состав электрода углеродных нанотрубок с высокой пористостью и долей транспортных пор и структурирования протонпроводящего полимера Nafion преимущественно в островковой форме.

\section{1. Теоретический анализ и использованные подходы}

Как хорошо известно, работу кислородно-водородного ТЭ лимитирует кислородный электрод-катод. Численные оценки, основанные на соотношении Батлера-Фольмера и других зависимостях, принятых 
в электрохимической кинетике [11], показывают, что экспериментально достигаемая габаритная плотность тока в катоде воздушно-водородного топливного элемента существенно ниже теоретически возможной, определяемой активностью платины. Так, в идеальном случае, при следующих исходных параметрах: ионное сопротивление протонпроводящей мембраны типа Nafion толщиной $50 \mu \mathrm{m} \sim(0.05-0.1) \Omega \cdot \mathrm{cm}^{2} \quad[12]$, плотность тока обмена кислородной реакции на поверхности электрохимически активной платины составляет $5.26 \cdot 10^{-6} \mathrm{~A} / \mathrm{cm}^{2}$; температура $80^{\circ} \mathrm{C}$ [13], плотность габаритного тока, определяемая активностью платины, без учета концентрационных потерь и в случае оптимальной структуры Nafion в электроде при $0.6 \mathrm{~V}$ составляет десятки $\mathrm{A} / \mathrm{cm}^{2}$ для поверхностной концентрации платины около $10^{-4} \mathrm{~g} / \mathrm{cm}^{2}$ при удельной площади поверхности платины $100 \mathrm{~m}^{2} / \mathrm{g}$. То есть теоретическая удельная загрузка платины в данном случае составит порядка $10^{-2} \mathrm{~g} / \mathrm{kW}$, что значительно лучше достигнутых в настоящее время результатов.

Известно, что главный вклад в потери эффективности катода вносят резистивные и диффузионные группы потерь. При этом за счет того, что ионное (протонное) сопротивление катода существенно выше его электронного сопротивления, основной вклад в резистивные потери вносит именно ионный транспорт. Эти потери обусловлены особенностями строения сетки частиц Nafion в структуре композитного электрода. Преобладание резистивных или диффузионных потерь зависит, как известно, от положения рабочей точки на ВАХ мембранно-электродного блока и габаритной плотности тока. Высокие плотности тока будут уже ограничиваться массовым транспортом - диффузией в пористом электроде.

Следовательно, мы имеем, по крайней мере, два структурно-зависимых фактора, воздействуя на которые можно увеличить эффективность электрода, и, следовательно, уменьшить удельную загрузку платины: эффективность ионного и массового транспорта.

С целью существенного уменьшения диффузионного сопротивления электрода использован хорошо зарекомендовавший себя прием увеличения его пористости за счет увеличения характерного диаметра пор путем введения в состав электрода углеродных структур, образующих каркасную структуру с очень высокой пористостью и порами большого диаметра $[14,15]$. В качестве такого материала использованы углеродные нанотрубки.

Одной из существенных проблем электродных материалов с увеличенной пористостью за счет крупных пор является увеличение ионного сопротивления в результате локальных разрывов сетки Nafion и исключения части поверхности платины из электрохимического процесса из-за отсутствия Nafion вблизи поверхности платины [16,17]. Для минимизации этого эффекта использовали увеличенное содержание Nafion островковой структуры [18] и оптимизацию состава электродного материала.

\section{2. Материалы и методы}

\section{1. Образцы}

В процессе исследования была изготовлена серия образцов электродного материала системы: Pt/C-CNT (carbon nanotubes)-Nafion с фиксированным массовым отношением $\mathrm{Pt} / \mathrm{C}: \mathrm{CNT}=1: 1$ и различным содержанием Nafion. На основе этих материалов изготовлены мембранно-электродные блоки с симметричными по загрузке материала электродами. МЭБ были исследованы методами вольт-амперных характеристик (BAX) и электрохимического импеданса с целью получения зависимости резистивных потерь от содержания Nafion.

В качестве углеродных нанотрубок использовали многостенные углеродные нанотрубки типа Таунит МД (производство ООО "НаноТехЦентр Тамбов) [19], платинированную углеродную сажу с массовым содержанием платины 40\% (коммерческий продукт марки Е-TEK) и коммерческий раствор Nafion.

Технологические операции приготовления дисперсии электродного материала для изготовления МЭБ включали две стадии: механическое и ультразвуковое диспергирование смеси точных навесок компонентов в смеси и-пропанол-вода. Объемное соотношение жидких составляющих и-пропанол: вода находилось в диапазоне $1: 1-1: 5$. Отношение твердой фазы к жидкой (т:ж) в конечной дисперсии при этом находилось в диапазоне $1: 40-1: 80$. Формирование электродов проводили способом, предусматривающим предварительное коагулирование Nafion из его раствора в жидкой фазе с последующим введением в структуру электрода [20]. Для этого коммерческий раствор Nafion в заданной концентрации перед добавлением в дисперсию разбавляли водой в объемном отношении $1: 1$.

Механическое диспергирование выполняли на магнитной мешалке типа Milaform MM-5M со скоростью вращения якоря $\sim 400$ оборотов в минуту с изолированным в пластиковый кожух якорем до визуально однородной (без видимых комочков) массы $\sim 0.5 \mathrm{~h}$. Последующее ультразвуковое диспергирование проводили в ультразвуковой ванне типа Branson 3510 в течение 40-100 h до получения однородной, не расслаивающейся в течение 1 min дисперсии.

МЭБ были изготовлены путем нанесения однородной дисперсии компонентов непосредственно на протонпроводящую мембрану через маску из нержавеющей стали. Перед нанесением электродного материала мембрану выдерживали в $0.5 \mathrm{M}$ серной кислоте в течение 15 min при температуре $70-80^{\circ} \mathrm{C}$ с последующей пятикратной промывкой водой. Электроды изготавливали методом намазывания дисперсии компонентов в смеси изопропанол-вода на протонпроводящую мембрану типа Nafion (марка МФ4-СК) толщиной $50 \mu \mathrm{m}$. Мембрану термостатировали при $85^{\circ} \mathrm{C}$ на плитке типа Ika C-MAG HP 7 с терморегулятором. Количество нанесенного материала контролировали гравиметрически. 
Модифицирование пористой структуры проводили введением в электрод на стадии приготовления углеродных нанотрубок типа Таунит МД с каркасной структурой и высокой пористостью. По нашим данным вычисления пористости этого материала на основании измерения насыпной плотности пористость составляет $\sim 98 \%$.

\section{2. Методы исследования}

Компонентный состав электродных материалов контролировали гравиметрически (методом термогравиметрического анализа) на дериватографе типа METTLER TOLEDO типа TGA/DSC 1 STAReSystem. Для этого навеску материала, массой несколько миллиграмм помещали в алундовый тигель, который помещали в камеру дериватографа. Далее проводили нагревание образца в интервале температур $35-1000^{\circ} \mathrm{C}$ со скоростью $10^{\circ} \mathrm{C} / \min$ в воздушной среде. При этом регистрировали массовую и тепловую температурные зависимости. Для получения данных о компонентном составе при обработке результатов дифференциально-термического анализа (ДТА) использовали два подхода.

Первый. По убыли массы образца на характерных для каждого компонента температурных интервалах измеряли количество Nafion $\left(260-360^{\circ} \mathrm{C}\right)$, углеродной сажи $\left(360-530^{\circ} \mathrm{C}\right), \mathrm{CNT}\left(530-700^{\circ} \mathrm{C}\right)$. По массе остатка в конце эксперимента $\left(1000^{\circ} \mathrm{C}\right)$ определяли количество платины. Ступени на массовой кривой соотносили с тепловыми эффектами (экзотермическими) на тепловой (дифференциальной термической) кривой для более четкого определения границ каждого процесса.

Второй. Количество сажи вычисляли исходя из оставшегося количества платины и состава платинированной сажи $(40 \% \mathrm{Pt}, 60 \% \mathrm{C})$. Количество CNT вычисляли по разности: убыль массы в интервале $360-700^{\circ} \mathrm{C}$ минус количество сажи, вычисленное по платине. Количество Nafion вычисляли методом, использованным в первом случае. Оба подхода показали сопоставимые результаты, которые также хорошо согласовались с составом по загрузке. Однако в первом случае происходит взаимное наложение температурных областей окисления углеродных материалов, что приводит к некоторому искажению результатов, поэтому за основу взят второй метод.

Толщину электродов измеряли толщиномером с разрешением $0.5 \mu \mathrm{m}$ в 10 точках слоя. За результирующее значение толщины принимали среднее арифметическое. Площадь электродов составляла $1 \mathrm{~cm}^{2}$. Пористость электродов вычисляли исходя из известного компонентного состава, толщины и площади по соотношению

$$
P=1-\frac{\sum_{i=1}^{n} \frac{\omega_{i} \cdot G}{d_{i}}}{V},
$$

где $P$ - пористость (объемная доля пор) электрода; $V$ - объем электрода (в данном случае при длине и ширине электрода по $1 \mathrm{~cm}$, объем численно равен
Изменение пористости электрода с добавкой CNT на различных участках концентрации Nafion

\begin{tabular}{c|c}
\hline $\begin{array}{c}\text { Интервал содержаний Nafion, } \\
\% \text { mass. }\end{array}$ & $\begin{array}{c}\text { Изменение пористости, } \\
\%\end{array}$ \\
\hline $10-25$ & $78-76$ \\
$25-40$ & $76-70$ \\
$40-60$ & $70-53$ \\
$60-80$ & $53-29$
\end{tabular}

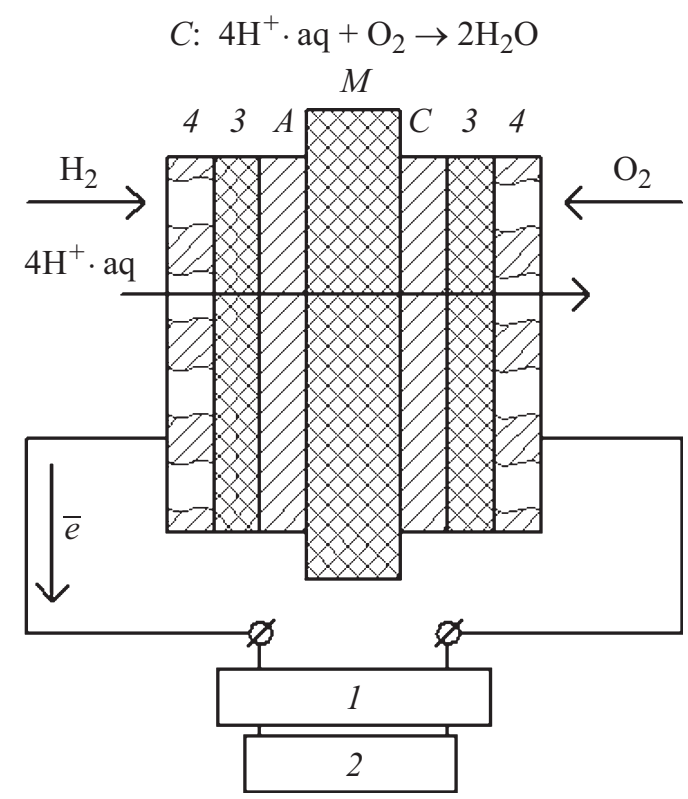

Рис. 1. Схема измерительной электрохимической ячейки: $C, A$ - пористые электроды, катод и анод соответственно; $M$ - протонпроводящая мембрана типа Nafion; 1 - потенциостат; 2 - управляющий компьютер; 3,4 - газораспределительные и газоподводящие каналы соответственно.

толщине); $\omega_{i}-$ массовая доля $i$-го компонента; $G-$ масса электрода; $d_{i}$ - плотность $i$-го компонента.

Объемную долю Nafion вычисляли исходя из его объема во влажном состоянии и объема электрода. При этом нами установлено, что геометрические параметры электрода в сухом и во влажном состояниях одинаковы в пределах погрешности измерений, т. е. он имеет жесткую каркасную структуру.

Перед проведением электрохимических измерений МЭБ выдерживали в $0.5 \mathrm{M}$ серной кислоте в течение 15 min при температуре $70-80^{\circ} \mathrm{C}$ с последующей пятикратной промывкой водой.

При проведении электрохимических измерений МЭБ помещали в стандартную электрохимическую ячейку (FC-05-02) с графитовыми токосъемными электродами производства ElectroChem, Inc.'s [21], схема которой приведена на рис. 1. ВАХ регистрировали при скорости развертки потенциала $0.01 \mathrm{~V} / \mathrm{s}$. МЭБ предварительно активировали методом, описанным в [22]. 
BAX регистрировали с использованием потенциостата типа Р-150 (производство ООО „Элинс“, Черноголовка) в среде кислород/водород при относительной влажности газов близкой к $100 \%$.

Ионное сопротивление измеряли, как описано в работе [23].

\section{3. Полученные результаты}

На рис. 2 приведены зависимости максимальной удельной мощности и удельного эффективного ионного сопротивления в рабочем режиме МЭБ с композитными электродами от содержания протонпроводящего полимеpa Nafion.

Как видно из рисунка, ионное сопротивление резко падает при увеличении содержания Nafion до 25\%. При дальнейшем увеличении концентрации Nafion, в интервале (25-60)\% ионное сопротивление незначительно растет и существенно увеличивается в интервале $(60-80) \%$. Причины увеличения ионного сопротивления рассмотрены в [24] и связаны с уменьшением доли центров образования воды. Максимальная удельная мощность имеет обратную зависимость. Она имеет высокие значения в интервале содержаний Nafion (25-40)\%, что соответствует началу участка незначительного увеличения ионного сопротивления. При уменьшении содержания Nafion с 25 до 10\%, и увеличении от 40 до $80 \%$ удельная мощность сильно уменьшается.

На рис. 3 приведена кривая зависимости пористости электродов от содержания Nafion.

Анализ изменения пористости на участках содержания Nafion, рассмотренных выше, показывает (см. таблицу), что она изменяется нелинейно. Так, в интервале концентраций Nafion (25-40)\% пористость уменьшается

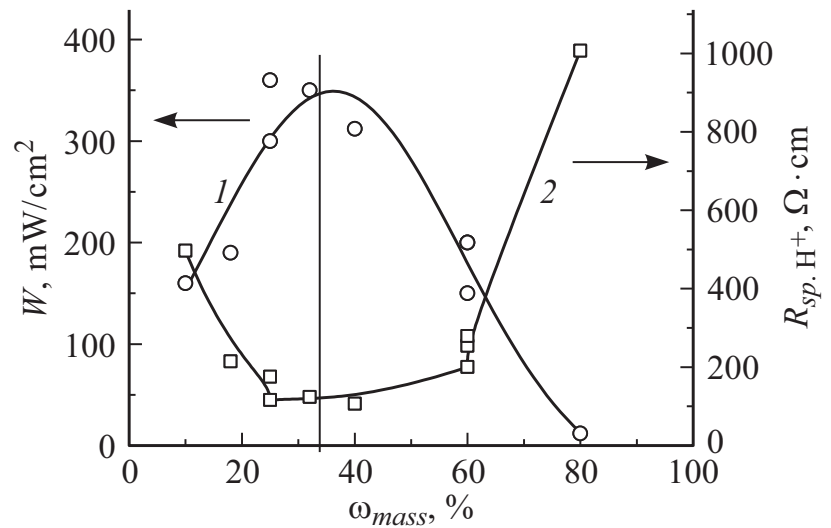

Pис. 2. Зависимости максимальной удельной мощности (1) и удельного эффективного ионного сопротивления в рабочем режиме МЭБ (2) от содержания Nafion; загрузка платины в катоде $0.1-0.17 \mathrm{mg} / \mathrm{cm}^{2}$; соотношение $\mathrm{Pt} / \mathrm{C}: \mathrm{CNT}=1$; измерено в системе $\mathrm{O}_{2} / \mathrm{H}_{2}$ при $25^{\circ} \mathrm{C}$, атмосферном давлении, скорость поляризации $10 \mathrm{mV} / \mathrm{s}$, поток кислорода $30 \mathrm{ml} / \mathrm{min}$, замкнутое анодное пространство с периодической продувкой с интервалом $100 \mathrm{~s}$

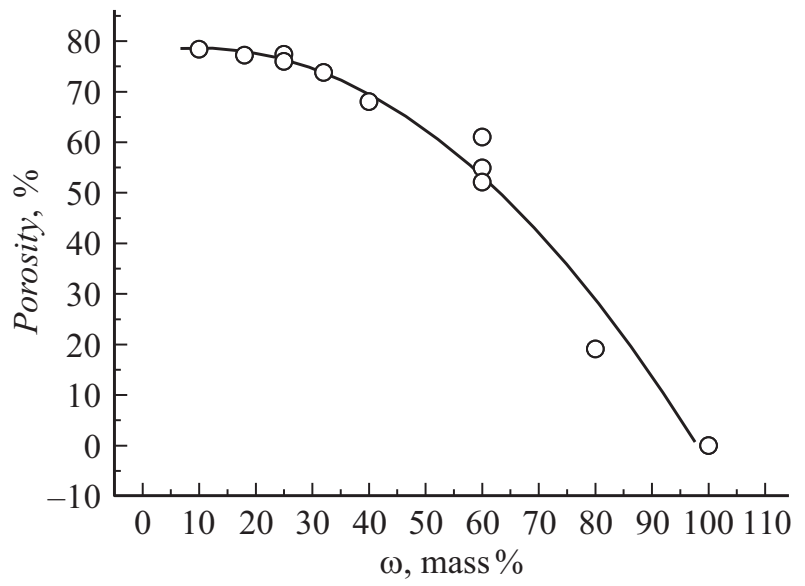

Рис. 3. Зависимость пористости электрода (образец с CNT) от содержания Nafion.

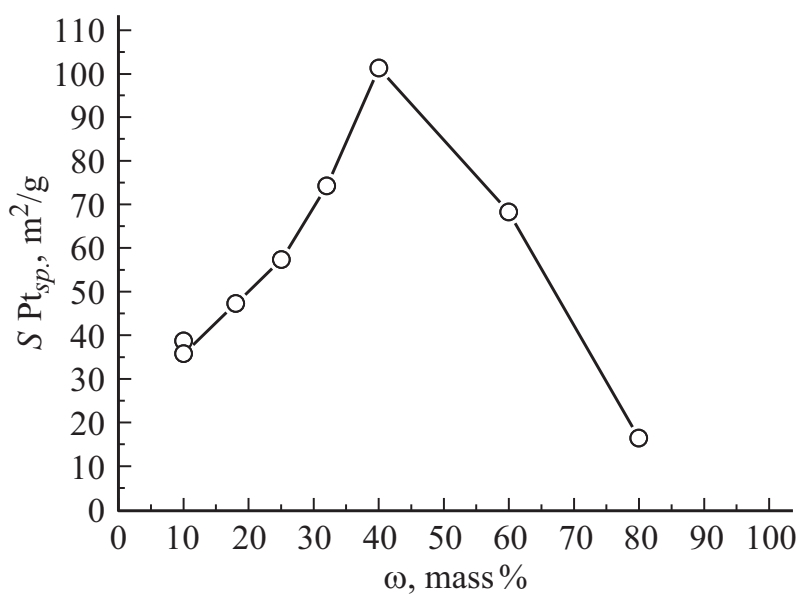

Рис. 4. Зависимость удельной площади поверхности платины от содержания Nafion в образце, содержащем CNT.

на 6\%, тогда как в интервале (40-60)\% Nafion пористость уменьшается на $23 \%$.

На рис. 4 приведена зависимость удельной площади поверхности платины от концентрации Nafion в электроде. Зависимость имеет максимум при 40\% Nafion. При этом экспериментально полученная величина площади поверхности платины близка к теоретически возможной. Исходя из общепринятых представлений, можно заключить, что левая возрастающая ветвь связана с развитием межфазной области при увеличении содержания Nafion. То есть по мере увеличения концентрации Nafion все больше платины вовлекается в сферу электрохимического процесса за счет образования межфазной области (платина-Nafion-водород). Правая нисходящая ветвь связана с блокированием части поверхности платины избыточным полимером Nafion.

Скорость электродного процесса, как известно, лимитируется наиболее медленной его составляющей: реакция переноса заряда, диффузия. Таким образом, на 


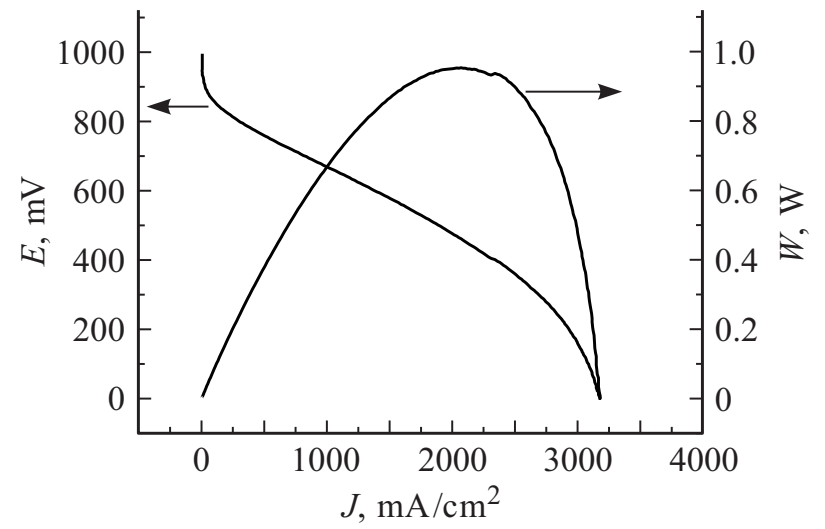

Рис. 5. Электрические характеристики МЭБ с электродами состава $34 \% \mathrm{Pt} / \mathrm{C}(40 \% \mathrm{Pt})-34 \% \mathrm{CNT}-32 \%$ Nafion в системе $\mathrm{O}_{2} / \mathrm{H}_{2}$ при температуре $80^{\circ} \mathrm{C}$, избыточном давлении $2 \mathrm{~atm}$, скорость поляризации $10 \mathrm{mV} / \mathrm{s}$.

основе анализа полученных экспериментальных зависимостей (рис. 2-4) можно сделать следующие выводы.

1. На участке содержания Nafion (10-25)\% увеличение удельной мощности происходит за счет уменьшения ионного сопротивления и увеличения площади поверхности платины. Массовый транспорт (диффузия) не является лимитирующим, так как пористость на этом участке наибольшая и падает незначительно.

2. На участке содержания Nafion (25-40)\% удельная мощность стабилизируется на высоком значении и лимитируется ионным сопротивлением. Возрастание удельной площади поверхности платины может быть частично компенсировано уменьшением пористости (увеличением сопротивления массовому транспорту).

3. На участке содержания Nafion (40-60)\% все большее влияние начинает оказывать лимитирующее действие массового транспорта, так как ионное сопротивление увеличивается незначительно, а пористость существенно уменьшается. При этом площадь поверхности платины остается на том же уровне, что и на участке $25-40 \%$ Nafion.

4. На участке содержания Nafion (60-80)\% уменьшение удельной мощности связано с увеличением газового диффузионного сопротивления вследствие существенного уменьшения пористости и ионного сопротивления изза недостаточного увлажнения Nafion.

Интервал (25-40)\% Nafion соответствует интервалу оптимальных составов модифицированного электрода и позволяет достигать максимальной удельной мощности и эффективности МЭБ. На основе полученных данных изготовлен МЭБ со следующими характеристиками (рис. 5).

На рис. 5 приведены ВАХ и мощностная характеристика МЭБ, содержащего 32\% Nafion. Загрузка платины в катоде составила $\sim 0.1 \mathrm{mg} / \mathrm{cm}^{2}$. Таким образом, при электрическом КПД $\sim 50 \%$ удельная загрузка платины составила $0.1 \mathrm{~g} / \mathrm{kW}$, а максимальная удельная мощность
$1 \mathrm{~W} / \mathrm{cm}^{2}$, что соответствует достигнутому на настоящий момент мировому уровню.

\section{Заключение}

1. За счет модифицирования структуры катода углеродными нанотрубками с высокой долей транспортных пор и структурирования Nafion преимущественно в островковой форме увеличена эффективность катодного процесса и улучшены характеристики катода.

2. Проведена оптимизация состава композитного катода по плотности мощности, интервал $(25-40) \%$ Nafion является оптимальным для системы $\mathrm{Pt} / \mathrm{C}(40 \% \mathrm{Pt})-\mathrm{CNT}-\mathrm{Nafion}$ при массовом отношении $\mathrm{Pt} / \mathrm{C}: \mathrm{CNT}=1$, для состава $34 \% \mathrm{Pt} / \mathrm{C} \quad\left(\begin{array}{lll}40 \% & \mathrm{Pt}\end{array}\right)-34 \%$ CNT-32\% Nafion получен МЭБ с мощностными характеристиками $\left(1 \mathrm{~W} / \mathrm{cm}^{2}\right)$, соответствующими мировому уровню при низкой $\left(0.1 \mathrm{mg} / \mathrm{cm}^{2}, 0.1 \mathrm{~g} / \mathrm{kW}\right)$ загрузке $\mathrm{Pt}$.

3. Проведенные исследования и разработанная технология позволяют создавать композитные электроды с высокой эффективностью, используя достаточно дешевые и простые методы, что особенно важно при промышленном изготовлении топливных элементов.

\section{Благодарности}

Глебова Н.В. благодарит стипендию президента № СП-2407.2018.1 за финансовую поддержку исследований.

\section{Конфликт интересов}

Авторы заявляют, что у них нет конфликта интересов.

\section{Список литературы}

[1] Papadias D.D., Ahluwalia R.K., Kariuki N., Myers D., More K. L., Cullen D.A., Sneed B.T., Neyerlin K.C., Mukundan R., Borup R.L. // J. Electrochem. Soc. 2018. Vol. 165. N 6. P. F3166-F3177. DOI: 10.1149/2.0171806jes

[2] Furuya Y., Iden H., Mashio T., Ohma A., Shinohara K. // ECMS Meeting. 2012. abstract 1522.

[3] Weber A.Z., Newman J. // Chem. Rev. 2004. Vol. 104. P. 4679-4726. DOI: 10.1021/cr0207291

[4] Чирков Ю.Г., Ростокин В.И. // Электрохимия. 2013. T. 49. № 5. C. 480-494. DOI: 10.1134/S1023193513020055 [Chirkov Y.G., Rostokin V.I. // Russ. J. Electrochem. 2013. Vol. 49. N 2. P. 149-160. DOI: 10.1134/S1023193513020055]

[5] Passalacqua E., Lufrano F., Squadrito G., Patti A., Giorgi L. // Electrochim. Acta. 2001. Vol. 46. IN 6. P. 799 805. DOI: $10.1016 / \mathrm{S} 0013-4686(00) 00679-4$

[6] Электронный ресурс. Режим доступа: URL: http://ma.ecsdl. org/content/MA2014-02/21/1082.abstract

[7] Chen D., Lin Z., Zhu H., Kee R.J. // J. Power Sources. 2009. Vol. 191. N 2. P. 240-252.

DOI: 10.1016/j.jpowsour.2009.02.051 
[8] Ji Hye Lee, Gisu Doo, Sung Hyun Kwon, Sungyu Choi, HeeTak Kim, Seung Geol Lee // Scientific Reports. 2018. Vol. 8. P. 10739. DOI: 10.1038/s41598-018-28779-y

[9] Алексеев Н.И., Бройко А.П., Калёнов В.Е., Корляков А.В., Лагош А.В., Лифиии А.О., Лучинин В.В., Хмельницкий И.К. // ЖСХ. 2018. Т. 59. № 7. С. 1766-1777. DOI: 10.26902/JSC20180726 [Alekseev N.I., Broiko A.P., Kalenov V.E., Korlyakov A.V., Lagosh A.V., Lifshits A.O., Luchinin V.V., Khmel'nitskii I.K. // J. Structural Chem. 2018. Vol. 59. N 7. P. 1707-1718.

DOI: $10.1134 / \mathrm{S} 0022476618070260]$

[10] Электронный ресурс. Режим доступа: URL: https://energy.gov/eere/fuelcells/downloads/fuel-celltechnologies-office-multi-year-research-development-and-22

[11] Zhang J. PEM Fuel Cell Electrocatalysts and Catalyst Layers. Vancouver: Springer, 2008. p. 1137.

[12] Slade S., Campbell S.A., Ralph T.R., Walsh F.C. // J. Electrochem. Soc. 2002. Vol. 149. N 12. P. A1556-A1564. DOI: $10.1149 / 1.1517281$

[13] Song C., Tang Y., Zhang J., Zhang J., Wang H., Shen J., McDermid S., Li J., Kozak P. // Electrochim. Acta. 2007. Vol. 52. N 7. P. 2552-2561.

DOI: $10.1016 /$ j.electacta.2006.09.008

[14] Нечитайлов А.А., Глебова Н.В., Краснова А.О., Томасов А.А., Зеленина Н.К. // ЖТФ. 2015. Т. 85. Вып. 11. C. 97-103. [Nechitailov A.A., Glebova N.V., Krasnova A.O., Tomasov A.A., Zelenina N.K. // Tech. Phys. 2015. Vol. 60. N 11. P. $1670-1676$.

[15] Krasnova A.O., Glebova N.V., Nechitaylov A.A. // Rus. J. Appl. Chem. 2016. Vol. 89. N 6. P. 916-920.

[16] Нечитайлов А.А., Глебова Н.В., Кошкина Д.В., Томасов A.A., Терукова E.E. // Альтернативная энергетика и экология. 2012. № 1 (105). С. 134-138.

[17] Glebova N.V., Nechitailov A.A., Krasnova A.O., Tomasov A.A., Zelenina N.K. // Rus. J. Appl. Chem. 2015. Vol. 88. N 5. P. 769-774. DOI: 10.1134/S1070427215050080

[18] Краснова А.О., Глебова Н.В., Нечитайлов А.А. // ЖПХ. 2016. Т. 89. Вып. 6. С. 756-761. DOI: $\quad 10.1134 / \mathrm{S} 1070427216060112 \quad[$ Krasnova A.O., Glebova N.V., Nechitaylov A.A. // Rus. J. Appl. Chem. 2016. Vol. 89. N 6. P. 916-920. DOI: 10.1134/S1070427216060112]

[19] Электронный ресурс. Режим доступа:

URL: http://www.nanotc.ru/producrions/87-cnm-taunit

[20] Litster S., McLean G. // J. Power Sources. 2004. Vol. 130. P. 61-76. DOI: 10.1016/j.jpowsour.2003.12.055

[21] Электронный ресурс. Режим доступа: URL: http://fuelcell.com/product/fc-05-02/

[22] Пат. РФ № 2487442 . Способ активации мембранноэлектродного блока. Д.А. Андроников, Н.К. Зеленина, Е.Е. Терукова, А.А. Томасов. 2013. Бюл. № 19.

[23] Глебова Н.В., Краснова А.О., Томасов А.А., Зеленина Н.К., Нечитайлов А.А. // ЖТФ. 2017. Т. 87. Вып. 6. С. 880-883. [Glebova N.V., Krasnova A.O., Tomasov A.A., Zelenina N.K., Nechitailov A.A. // Tech. Phys. 2017. Vol. 62. P. 895-898. DOI: $10.1134 / \mathrm{S} 106378421706010 \mathrm{X}]$

[24] Нечитайлов А.А., Глебова Н.В., Томасов А.А., Краснова А.О., Зеленина Н.К. // Письма в ЖТФ. 2018. Т. 44. Вып. 23. C. $120-128$.

DOI: 10.21883/PJTF.2018.23.47019.17324 